Original Article

\title{
Views of physiatrists and physical therapists on the use of gait-training robots for stroke patients
}

\author{
Chang Gu $\mathrm{Kang}^{1}{ }^{1}$, Min Ho Chun ${ }^{1)^{*}}$, Min Cheol Chang $^{1)}$, Won Kim ${ }^{1)}$, Kyung Hee Do ${ }^{1)}$ \\ 1) Department of Rehabilitation Medicine, Asan Medical Center, University of Ulsan College of \\ Medicine: 88 Olympic-Ro, 43-Gil, Songpa-gu, Seoul 138-736, Republic of Korea
}

\begin{abstract}
Purpose] Gait-training robots have been developed for stroke patients with gait disturbance. It is important to survey the views of physiatrists and physical therapists on the characteristics of these devices during their development. [Subjects and Methods] A total of 100 physiatrists and 100 physical therapists from 38 hospitals participated in our questionnaire survey. [Results] The most common answers about the merits of gait-training robots concern improving the treatment effects $(28.5 \%)$, followed by standardizing treatment (19\%), motivating patients about treatment (17\%), and improving patients' self-esteem (14\%). The subacute period (1-3 months poststroke onset) was most often chosen as the ideal period (47.3\%) for the use of these devices, and a functional ambulation classification of $0-2$ was the most selected response for the optimal patient status $(27 \%)$. The preferred model was the treadmill type (47.5\%) over the overground walking type (40\%). The most favored commercial price was $\$ 50,000-\$ 100,000$ (38.3\%). The most selected optimal duration for robot-assisted gait therapy was 30-45 min (47\%), followed by $15-30 \mathrm{~min}(29 \%), 45-60 \mathrm{~min}(18 \%), \geq 60 \mathrm{~min}(5 \%)$, and $<15 \min (1 \%)$. [Conclusion] Our study findings could guide the future designs of more effective gait-training robots for stroke patients.

Key words: Robot, Gait, Stroke
\end{abstract}

(This article was submitted Aug. 20, 2015, and was accepted Oct. 16, 2015)

\section{INTRODUCTION}

Gait disturbance is one of the most disabling sequelae of stroke ${ }^{1,2)}$, with a reported prevalence of $54-80 \%{ }^{3,4)}$. Gait disturbance often leads to loss of independence, which has profound effects on both the patients and the caregivers and results in higher health-care costs ${ }^{4-7}$. The management of gait disturbance is therefore essential for stroke rehabilitation. Several traditional gait rehabilitation techniques have been developed to improve gait disturbance in stroke patients, including neurophysiological techniques (e.g., the Bobath, Brunnström, proprioceptive neuromuscular facilitation, Vojta, and Rood methods $)^{8)}$ and motor learning techniques (e.g., the Perfetti, Carr and Shepherd, conductive education, and sensory integration methods $)^{9}$. However, these traditional methods are very physically intensive for the therapists, making it difficult for these practitioners to continuously provide gait training for stroke patients ${ }^{10)}$.

Robotic technology has progressed rapidly in recent years, and several gait-training robots have now been developed, including the Lokomat (Hocoma Inc., Volketswil, Switzerland) and G-EO (Rha Technologies, Olten, Switzerland). These devices use a powered exoskeleton with a treadmill (Lokomat) or powered footplates with programmable trajectories, or are analogous to a robotic elliptical trainer $(\mathrm{G}-\mathrm{EO})^{11)}$. These devices have alleviated the physical workload for the therapists and have thus gained popularity. Several studies have also suggested that gait-training robots can improve locomotor recovery in stroke patients ${ }^{12}$.

To aid in the further development and refinement of gait-training robots, it is important to survey the views of the physiatrists and physical therapists who might use these machines, in terms of merit, indication, type, price, treatment duration, and design. In our current study, these parameters were evaluated by means of a questionnaire survey.

*Corresponding author. Min Ho Chun (E-mail: mhchun@amc.seoul.kr)

(C2016 The Society of Physical Therapy Science. Published by IPEC Inc.

This is an open-access article distributed under the terms of the Creative Commons Attribution Non-Commercial No Derivatives (by-nc-nd) License $<$ http://creativecommons.org/licenses/by-nc-nd/3.0/>. 


\section{SUBJECTS AND METHODS}

A questionnaire was developed to collect the opinions of physiatrists and physical therapists on robot-assisted gait-training therapy. The questionnaire was divided into six sections: merit of robot-assisted gait training, indications for gait-training robots, robot type, treatment duration, price, and design of gait-training robots. On the basis of these six categories, a total of 46 questions were developed. Most questions were either closed ended (multiple choice), or based on a 10-point Likert scale that gauges the level of agreement with or feelings on the importance of an item. A total of 100 physiatrists and 100 physical therapists from 38 hospitals participated in the survey from November 2013 to May 2014. A self-written survey method was used, either face-to-face or by mail. A software was used to randomly enroll participants from the registry of physiatrists and physical therapists at the Korean Academy of Rehabilitation Medicine. This study was exempted from institutional review board (IRB) review requirements based on the guidelines of Asan Medical Center (IRB no. S-2013-1301-0006).

The SPSS version 18.0.0 software package was used for statistical analyses, and p-values $<0.05$ were considered to indicate statistically significant differences. Questions such as perspectives on the use of gait-training robots for stroke patients according to rehabilitation experience parameters were analyzed by using Pearson's chi-square test and ANOVA.

\section{RESULTS}

A total of 106 physiatrists and 107 physical therapists were invited to complete our study survey. Six physiatrists and seven physical therapists could not complete the survey for various reasons, resulting in a $94 \%$ participation rate. For 62 (31\%) participants, the surveys were conducted face-to-face. The remaining participants $(69 \%)$ completed the survey by mail. Concerning the experience of the study participants in providing rehabilitation to stroke survivors, $33 \%$ had worked with stroke survivors for $>5$ years, whereas $67 \%$ of these practitioners had worked with such patients for $1-5$ years. Sixtyseven (33.5\%) participants had a previous experience with using a rehabilitation robot. The survey questions asked about the perception of the treatment effects of gait-training robots by using a 10-point Likert scale for effectiveness. Participants with previous experience with a gait-training robot selected a higher score in this regard. The average score of this experienced group was 7.63, and that of the nonexperienced group was 6.93 (on a 10-point Likert scale, p $<0.001$; Table 1). A more detailed description of these statistics is provided in Table 2.

The survey included questions on the merit of robot-assisted gait training for stroke patients. The most selected answer was "improvement of treatment effects" $(28.5 \%)$, followed by "standardized treatment" (19\%), "triggering a patient's motivation for treatment" (17\%), and "elevation of a patient's self-esteem" (14\%).

The survey also queried the appropriate period to use a gait-training robot. At " $1-3$ months after stroke onset" (47.3\%) was the most frequently selected answer, followed by "3-6 months after stroke onset" $(27.4 \%)$, "within 1 month after stroke onset" (14.4\%), "6-12 months after stroke onset" (8\%), and "12 months after stroke onset" (3\%).

The survey participants were also asked about the appropriate locomotor status of a patient to warrant the application of a gait-training robot. Patient locomotor status was rated on the basis of a functional ambulation classification (FAC) score from 0 to 5 . The most selected response for the optimal patient locomotor status was "FAC 1" (27\%), followed by "FAC 2" (24\%), "FAC 0" (23\%), "FAC 3" (11\%), "FAC 4" (8\%), and "FAC 5" (2\%). The extent of agreement with the application of a gait-training robot at each locomotor status by using a 10-point Likert scale was also surveyed. The average scores for each locomotor status classification are reported in Table 3, and the mean scores for each locomotor status score showed an identical pattern.

The most useful type of gait-training robot for stroke patients was also surveyed. The most selected answer was the "treadmill type" (47.5\%), followed by the "overground walking type" (40\%), "foot plate-based gait trainer" $(11.5 \%)$, and "fixed-gait trainer" (1\%). The survey also asked about the appropriate treatment duration for robot-assisted gait therapy. The "30-45 min" period was selected most often (47\%), followed by "15-30 min" (29\%), "45-60 min" (18\%), " $\geq 60$ min" (5\%), and "< 15 min" $(1 \%)$.

When queried about the most suitable price for a gait-training robot for stroke patients, the survey participants most frequently selected "from $\$ 50,000$ to $\$ 100,000$ " (38.3\%), followed by “from $\$ 100,000$ to $\$ 200,000$ " (37.8\%), "below $\$ 50,000$ " (14.4\%), and "from $\$ 200,000$ to $\$ 500,000 "(8.5 \%)$.

The participants were also surveyed about design considerations. Most of the respondents selected "stability" (49\%), followed by "comfort" (28\%), "cutting edge" (13\%), "friendliness" (9\%), and "other" (1\%). When asked about the most important consideration for the production of gait-training robots, the most frequently selected answer was "convenience of on and off" (39.7\%), followed by "fitting sense" (23.9\%), "light weight" (23.2\%), "miniaturization" (10.2\%), and "aesthetics" $(3 \%)$. The most frequently selected response concerning the intention detector sensors for gait-training robots was "EMG" (electromyography) (25\%), followed by "foot pressure" (22\%), "joint torque" (20\%), "tilt sensor" (19\%), and "other" (14\%). When asked about the ideal graph type for training results, "bar graph" $(42.3 \%)$ was selected most often, followed by "line graph" (27.9\%), "radiant graph" (21.9\%), and "pie graph" (8.0\%). In terms of the most preferred materials for direct contact areas, most respondents to the survey selected "silicon" (60\%), followed by "leather" $(21 \%)$, "cloth" (13\%), "wood" (4\%), and "others" (2\%). 
Table 1. Perception of the treatment effects of a gait-training robot

\begin{tabular}{lcc}
\hline & Experienced & Nonexperienced \\
\hline $\begin{array}{l}\text { Treatment } \\
\text { effect }\end{array}$ & 7.63 & $6.93^{*}$ \\
\hline
\end{tabular}

Values are on a 10-point Likert scale. ${ }^{*} \mathrm{p}<0.05$ by using Fisher's exact test
Table 3. Average scores for each locomotor status

\begin{tabular}{lcc}
\hline & Mean & SD \\
\hline FAC 0 & 6.34 & \pm 2.37 \\
FAC 1 & 6.89 & \pm 1.94 \\
FAC 2 & 6.25 & \pm 2.10 \\
FAC 3 & 4.93 & \pm 2.41 \\
FAC 4 & 4.43 & \pm 2.44 \\
FAC 5 & 2.85 & \pm 2.60 \\
\hline
\end{tabular}

Values are on a 10-point Likert scale. FAC: functional ambulation classification

Table 2. Baseline characteristics of the study participants

\begin{tabular}{llc}
\hline & & $\mathrm{n}(\%)$ \\
\hline \multirow{3}{*}{ Gender } & Male & $137(68.5)$ \\
& Female & $63(31.5)$ \\
& Physiatrist & $100(50)$ \\
Career & Physical therapist & $100(50)$ \\
Experienced in gait rehabilitation & More than 5 years & $56(28)$ \\
with a gait-training robot & Less than 5 years & $144(72)$ \\
& Experienced & $67(33.5)$ \\
Institution of employment & Nonexperienced & $133(66.5)$ \\
& Tertiary hospital & $63(31.5)$ \\
& General hospital & $40(20)$ \\
& Rehabilitation hospital & $72(36)$ \\
& Care hospital & $25(12.5)$ \\
\hline
\end{tabular}

\section{DISCUSSION}

In our present study, the views of physiatrists and physical therapists on the use of gait-training robots were surveyed, specifically their views on the merits of robot-assisted gait training; the indications for using these devices; the optimal treatment duration of robot-assisted gait training; and the type, price, and design of gait-training robots.

The largest group of participants selected "treatment effect of gait training" as the principal reason that would merit robot-assisted gait training, followed by standardized treatment. This finding is consistent with those of previous reports showing that robot-assisted gait training exhibited equivalent or better treatment effects compared with conventional physical therapy ${ }^{11,13,14)}$. In conventional gait training by physical therapists, the protocols and intensities of this intervention can differ depending on the practitioner. By contrast, robot-assisted gait training can provide reproducible symmetrical gait kinematic patterns of leg movements ${ }^{15)}$, and thus enable standardized treatment to be continuously provided to stroke patients ${ }^{16)}$.

In the survey of experts, the most appropriate patient locomotor status for the application of gait-training robots was indicated to be an FAC score ranging from 0 to 2, which corresponds to patients who cannot walk without assistance ${ }^{17)}$. Conventional gait training thus imposes a significant physical burden on therapists when treating patients with FAC scores of $0-2^{18}$, and this approach could not therefore be readily applied on a large scale for such cases. Importantly, this limitation could be overcome by the application of robot-assisted gait training ${ }^{19)}$.

Our current study survey indicated that the most appropriate period to apply gait-training robots in stroke patients is at 1-3 months after the disease onset. This result concurs with previous reports of a significant improvement in walking speed and functional outcomes when these devices are used during the acute post-stroke phase $(2.5-14 \text { weeks })^{20-23)}$. Additionally, several clinical studies have reported that recovery from stroke mainly occurs during the first 3 months after its onset ${ }^{24-26)}$.

Treadmill gait-training robots were the most selected type in our survey, followed by overground walking-type robots. This finding was consistent with those of preliminary studies that suggested that the use of treadmill gait training leads to a better recovery of ambulation, with beneficial effects on overground walking speed and endurance, and a reduction in the physical assistance required to walk ${ }^{27-29}$. Conversely, fewer of our survey participants selected a foot plate-based gait trainer. This result was not surprising, as foot plate-based gait trainers are considered to have several drawbacks compared with other types of gait-training robots. First, foot plate-based gait trainers lack a true swing phase during the gait cycle ${ }^{30}$. Additionally, they cannot control spasticity of the lower extremities ${ }^{11)}$ and would be difficult to use for patients with a lower 
locomotor status (FAC 0-2).

The appropriate duration of a robot-assisted gait therapy session was considered to be 30-45 min by most of our survey respondents. This was also an unsurprising finding. A previous study has suggested that $>30$ min of gait training is effective in improving the locomotor function of stroke patients ${ }^{31}$. . Moreover, $>30 \mathrm{~min}$ of aerobic exercise is required for an improved cardiovascular function $^{32}$. However, a prolonged treatment duration can cause patients to experience physical fatigue and to lose interest in continuing the therapy ${ }^{33,34)}$.

Concerning the suitable price for a gait-training robot, the most commonly selected response was the $\$ 50,000-\$ 100,000$ range, followed by $\$ 100,000-\$ 200,000$. The most important requirements to consider in the design of a gait-training robot were considered by our survey participants to be (in order of importance): stability, comfort, cutting-edge features, and friendliness. Bar graphs were the most preferred graphical representations of real-time training states and training results, perhaps because these data are easier to comprehend. An EMG sensor was considered to be the most appropriate type for the detection of intended gait initiation. From these responses, we contend that gait-training robot producers should consider the results of our survey when designing and then manufacturing gait-training robots.

To the best of our knowledge, only one previous study has investigated the views of therapists on the optimal practices and design requirements for the development of an upper-limb stroke rehabilitation robot ${ }^{35}$. However, no study to date has surveyed the views of practitioners on their use of gait-training robots. Our current study is the first to investigate the actual user demands for gait-training robots, and to evaluate the perspectives on the use of these devices to help in the rehabilitation of stroke patients. A notable limitation of our current investigation was that only one-third of the participants had experience with robot-assisted gait training. Future studies should therefore enroll more participants with such an experience.

\section{ACKNOWLEDGEMENT}

This study was partially supported by the research and development program of the Ministry of Trade, Industry, and Energy/Korea Evaluation Institute of Industrial Technology (10045164).

\section{REFERENCES}

1) Mauritz KH: Gait training in hemiplegia. Eur J Neurol, 2002, 9: 23-29, 53-61. [Medline] [CrossRef]

2) You YY, Chung SH: The effects of gait velocity on the gait characteristics of hemiplegic patients. J Phys Ther Sci, 2015, 27: 921-924. [Medline] [CrossRef]

3) Jørgensen HS, Nakayama H, Raaschou HO, et al.: Recovery of walking function in stroke patients: the Copenhagen Stroke Study. Arch Phys Med Rehabil, 1995, 76: 27-32. [Medline] [CrossRef]

4) Cho KH, Lee JY, Lee KJ, et al.: Factors related to gait function in post-stroke patients. J Phys Ther Sci, 2014, 26: 1941-1944. [Medline] [CrossRef]

5) Hong E: Comparison of quality of life according to community walking in stroke patients. J Phys Ther Sci, 2015, 27: 2391-2393. [Medline] [CrossRef]

6) Evers SM, Struijs JN, Ament AJ, et al.: International comparison of stroke cost studies. Stroke, 2004, 35: 1209-1215. [Medline] [CrossRef]

7) Schaechter JD: Motor rehabilitation and brain plasticity after hemiparetic stroke. Prog Neurobiol, $2004,73:$ 61-72. [Medline] [CrossRef]

8) Bobath B: Adult hemiplegia: evaluation and treatment, 3rd ed. Oxford: Butterworth-Heinemann, 1990.

9) Carr JH: Stroke rehabilitation: guidelines for exercise and training to optimize motor skill. Oxford: ButterworthHeinemann, 2003.

10) Bensoussan L, Mesure S, Viton JM, et al.: Kinematic and kinetic asymmetries in hemiplegic patients' gait initiation patterns. J Rehabil Med, 2006, 38: 287-294. [Medline] [CrossRef]

11) Hornby TG, Campbell DD, Kahn JH, et al.: Enhanced gait-related improvements after therapist- versus robotic-assisted locomotor training in subjects with chronic stroke: a randomized controlled study. Stroke, 2008, 39: 1786-1792. [Medline] [CrossRef]

12) Bae YH, Ko YJ, Chang WH, et al.: Effects of robot-assisted gait training combined with functional electrical stimulation on recovery of locomotor mobility in chronic stroke patients: a randomized controlled trial. J Phys Ther Sci, 2014, 26: 1949-1953. [Medline] [CrossRef]

13) Fisher S, Lucas L, Thrasher TA: Robot-assisted gait training for patients with hemiparesis due to stroke. Top Stroke 
Rehabil, 2011, 18: 269-276. [Medline] [CrossRef]

14) Westlake KP, Patten C: Pilot study of Lokomat versus manual-assisted treadmill training for locomotor recovery poststroke. J Neuroeng Rehabil, 2009, 6: 18. [Medline] [CrossRef]

15) Hornby TG, Zemon DH, Campbell D: Robotic-assisted, body-weight-supported treadmill training in individuals following motor incomplete spinal cord injury. Phys Ther, 2005, 85: 52-66. [Medline]

16) Hesse S, Tomelleri C, Bardeleben A, et al.: Robot-assisted practice of gait and stair climbing in nonambulatory stroke patients. J Rehabil Res Dev, 2012, 49: 613-622. [Medline] [CrossRef]

17) Williams G: Functional ambulation classification. In: Kreutzer JS, DeLuca J, Caplan B, eds. Encyclopedia of clinical neuropsychology. New York: Springer, 2011, pp 1105-1106.

18) Banala SK, Kim SH, Agrawal SK, et al.: Robot assisted gait training with active leg exoskeleton (ALEX). IEEE Trans Neural Syst Rehabil Eng, 2009, 17: 2-8. [Medline] [CrossRef]

19) Morone G, Bragoni M, Iosa M, et al.: Who may benefit from robotic-assisted gait training? A randomized clinical trial in patients with subacute stroke. Neurorehabil Neural Repair, 2011, 25: 636-644. [Medline] [CrossRef]

20) Peurala SH, Tarkka IM, Pitkänen K, et al.: The effectiveness of body weight-supported gait training and floor walking in patients with chronic stroke. Arch Phys Med Rehabil, 2005, 86: 1557-1564. [Medline] [CrossRef]

21) Tong RK, Ng MF, Li LS: Effectiveness of gait training using an electromechanical gait trainer, with and without functional electric stimulation, in subacute stroke: a randomized controlled trial. Arch Phys Med Rehabil, 2006, 87: 1298-1304. [Medline] [CrossRef]

22) Schwartz I, Sajin A, Fisher I, et al.: The effectiveness of locomotor therapy using robotic-assisted gait training in subacute stroke patients: a randomized controlled trial. PM R, 2009, 1: 516-523. [Medline] [CrossRef]

23) Pohl M, Werner C, Holzgraefe M, et al.: Repetitive locomotor training and physiotherapy improve walking and basic activities of daily living after stroke: a single-blind, randomized multicentre trial (DEutsche GAngtrainerStudie, DEGAS). Clin Rehabil, 2007, 21: 17-27. [Medline] [CrossRef]

24) Kramer SF, Churilov L, Kroeders R, et al.: Changes in activity levels in the first month after stroke. J Phys Ther Sci, 2013, 25: 599-604. [Medline] [CrossRef]

25) Duncan PW, Goldstein LB, Matchar D, et al.: Measurement of motor recovery after stroke. Outcome assessment and sample size requirements. Stroke, 1992, 23: 1084-1089. [Medline] [CrossRef]

26) Richards CL, Olney SJ: Hemiparetic gait following stroke. Part II: Recovery and physical therapy. Gait Posture, 1996, 4: 149-162. [CrossRef]

27) Takami A, Wakayama S: Effects of partial body weight support while training acute stroke patients to walk backwards on a treadmill: a controlled clinical trial using randomized allocation. J Phys Ther Sci, 2010, 22: 177-187. [CrossRef]

28) Hesse S, Bertelt C, Jahnke MT, et al.: Treadmill training with partial body weight support compared with physiotherapy in nonambulatory hemiparetic patients. Stroke, 1995, 26: 976-981. [Medline] [CrossRef]

29) Visintin M, Barbeau H: The effects of body weight support on the locomotor pattern of spastic paretic patients. Can J Neurol Sci, 1989, 16: 315-325. [Medline]

30) Hussein S, Kruger J: Patient adaptive control of end-effector based gait rehabilitation devices using a haptic control framework. IEEE Int Conf Rehabil Robot, 2011, 2011: 5975451. [Medline]

31) Plummer P, Behrman AL, Duncan PW, et al.: Effects of stroke severity and training duration on locomotor recovery after stroke: a pilot study. Neurorehabil Neural Repair, 2007, 21: 137-151. [Medline] [CrossRef]

32) McCormick ZL, Lynch M, Liem B, et al.: Feasibility for developing cardiovascular exercise recommendations for persons with motor-complete paraplegia based on manual wheelchair propulsion; a protocol and preliminary data. J Spinal Cord Med, 2015. [Medline] [CrossRef]

33) Inoue $\mathrm{K}$, Uematsu M, Maruoka H, et al.: Influence of lower limb muscle fatigue on balance function. J Phys Ther Sci, 2013, 25: 331-335. [CrossRef]

34) Langhorne P, Wagenaar R, Partridge C: Physiotherapy after stroke: more is better? Physiother Res Int, 1996, 1: 75-88. [Medline] [CrossRef]

35) Lu EC, Wang RH, Hebert D, et al.: The development of an upper limb stroke rehabilitation robot: identification of clinical practices and design requirements through a survey of therapists. Disabil Rehabil Assist Technol, 2011, 6: 420-431. [Medline] [CrossRef] 